\title{
Motivations, contradictions and ambiguities in the leadership of nurses in management positions in a university hospital
}

\author{
Clarice Maria Dall'Agnol' ${ }^{1}$ \\ Gisela Maria Schebella Souto de Moura² \\ Ana Maria Muller de Magalhães² \\ Maria Lúcia Rodrigues Falk ${ }^{3}$ \\ Caren de Oliveira Riboldi ${ }^{3}$ \\ Andréia Peres de Oliveira ${ }^{4}$
}

Objective: to analyze the contradictions and ambiguities which permeate nurses' motivation for exercising leadership in management positions, in a university hospital. Method: this study has a qualitative approach and is exploratory and descriptive, and used a total of 33 semi-structured interviews which were submitted to thematic analysis. Results: the information converged on five categories: Motivation to take on a management position; The view of nursing managers on the exercising of leadership; The emblematic aspect of working with people; Leadership in nursing - mediatory and conciliatory; Time: a dilemma between managing and caring. Conclusion: leading people can be both a great encouragement, and an impeding aspect, bearing in mind the nuances of teamwork and the complexity of the context in which this process is constructed. In addition to this, conciliatory and mediatory attitudes are shown to be fundamental for a healthy and productive organizational atmosphere; however, the lack of time was indicated as a dilemma between managing and caring.

Descriptors: Leadership; Health Management; Nursing, Team.

\footnotetext{
${ }^{1} \mathrm{PhD}$, Associate Professor, Escola de Enfermagem, Universidade Federal do Rio Grande do Sul, Porto Alegre, RS, Brazil. ${ }^{2}$ PhD, Adjunct Professor, Escola de Enfermagem, Universidade Federal do Rio Grande do Sul, Porto Alegre, RS, Brazil. ${ }^{3}$ MSc, RN, Hospital de Clínicas de Porto Alegre, Porto Alegre, RS, Brazil.

${ }^{4}$ Master's student, Escola de Enfermagem, Universidade Federal do Rio Grande do Sul, Porto Alegre, RS, Brazil. RN, Hospital Mãe de Deus, Porto Alegre, RS, Brazil.
} 


\section{Introduction}

The university hospitals have been the focus of discussion in various forums in Brazil regarding the carrying-out of health and nursing actions, considering the proposal of integrating assistance, teaching and research, as well as developing technological training and innovation, being scenarios which make a rich articulation between training institutions and health care services possible. It is important to highlight that academic-assistential integration has contributed to the qualification of the attendance and investigative actions in the search for responses to the population's health problems, as well as to the implementation of State policies in the Unified Health System (SUS) ${ }^{(1-2)}$.

The university hospitals have an unalienable commitment to offering health services to the community. At the same time, they function as a prolonging of the university environment, both in the training of professionals and in the creation of knowledge, through teaching and research. However, the link between the three areas is not exempt from tensions in the daily routine. At times, it is argued that that greater importance should be given to the care, this being an unchallenged commitment; at others, that teaching and research should be prioritised, the allegation being made that the environment is academic. Contingent factors arising from public health policies further intensify the discussion.

Although the university hospitals benefit from being publicly recognized as centers of excellence in high complexity-care, the advances in technological and scientific development - in these hospitals - still cannot rely on improvement and modernization of their management models, as these continue to be environments with centralization of power and bureaucratic and inflexible structures, as well as little space for democratic actions(3). In such settings, one faces the imperative need to understand the phenomenon of leadership, markedly in strategic positions of management, as is the case of nurses in management positions. This is a question which has aroused the curiosity of academics and researchers in the area of administration and also of other professional areas which are supported by this science. Nursing, in this context, has been appropriating the knowledge of administrative science, so as to conduct its routine work better. In a dynamic movement, the transposition of concepts, propositions and models creates new knowledge and questions to be investigated.
As the world of work has been passing through transformations and paradigm shifts, the leadership exercised by the nurses in the health organizations is passing through a period of transition. The current tendencies indicate that the nurses need to move on from the more rigid and hierarchized models to styles of leadership which are more flexible and democratic, creating collective spaces for discussion ${ }^{(4)}$. In order to implement innovative management, able to put into action the changes required by the context and, at the same time, meet the objectives of the professionals and the organizational goals, it is fundamental to train the nurses to exercise leadership and their communication skills ${ }^{(5)}$.

These considerations refer to the specific characteristics of the nursing work, particularly teamwork, the nurse having the central position of coordinator of these efforts, recognizing leadership as an issue of fundamental importance in achieving organizational and collective objectives in the organization of the work. The emphasis attributed to the leader in teamwork emphasizes the need for a more attent eye on this process, transcending the mere occupation of formal positions in the hospital structure. What is expected are managers who are truly leaders, who undertake strategic and integrative coordination, articulating a collective and participative work grounded in responsibility, trust and transparency in the management process ${ }^{(6)}$. However, the achievement of this requirement does not occur in a linear fashion, as, in exercising leadership, movements of coming and going are involved, as are conflict resolution, decisionmaking and achieving results. This is a dynamic in which the nurse constantly faces situations in which values, competences and attitudes, both personal and professional, are put to the test. These considerations lead to the research question: What contradictions and ambiguities permeate the nurses' motivation for exercising leadership in management positions? In the face of this question, this study was undertaken, with the objective of analyzing the contradictions and ambiguities which permeate the nurses' motivation for exercising leadership in management positions in a university hospital.

\section{Method}

With a perspective of qualitative research, an exploratory-descriptive study was carried out in a public university hospital in the South region of Brazil. It had 
795 inpatient treatment beds and a workforce totalling 5,546 staff, with 2010 nursing professionals, of whom 505 are nurses.

The sample was of the census type, with the following inclusion criteria adopted: nurses who had been exercising management for a minimum of one month and who were not on leave due to holidays, special leave, health treatment or maternity leave. Thus, of the 37 health care centers, including inpatient areas and closed areas (the sterilized materials center and the operating theaters etc.), 33 nurses in management positions in these sectors participated. All (100\%) were women and the mean age corresponded to $45 \pm 6.9$ years old; the mean length of professional service was $21 \pm 7.3$ years, with the mean length of work in the institution being $17.9 \pm 8$ years; of the total of the participants, $15(45 \%)$ had been exercising the role of manager for one year, and $27(82 \%)$ had had previous experience in this activity. In relation to professional training, 26 (79\%) had a post-graduate specialization course, with a predominance of courses in the area of management, and $7(21 \%)$ had post-graduate qualifications at Master's level, either concluded or ongoing.

Data collection took place between April and June 2010, through semi-structured interviews which were held in a classroom, in the hospital itself, during the work shift, by previous agreement, and which were recorded and later transcribed. Among the questions, the participants were asked about what encouraged or motivated them to take on management positions, the aim being to identify facilitating and/or impeding aspects related to leadership, in this process, which showed contradictions and ambiguities.

Descriptive statistics was used to organize the data relating to the participants' profile, mentioned above. The information arising from the semi-structured questions was submitted to categorical analysis of the thematic type, which consists in discovering the nuclei of meaning which make up a communication, and the presence of themes which denote reference values and the behavioral models present in the reports(7).

In order to undertake the research, the requirements of Resolution 196/96 of the National Health Council(8) were met; the project, registered as 09-251, was approved by the research ethics committee of the institution where the study was to be held. The participants signed the Terms of Free and Informed Consent, keeping one copy and leaving the other in the possession of the researchers. Emphasis was placed on the confidential nature of the information, the preservation of anonymity, and the right of free participation was assured, without this being able to lead to embarrassment or any prejudice to the participants.

\section{Results and Discussion}

The surveying, exploration and interpretation of the material resulted in five categories, described below.

\section{Motivation for taking on the management position}

The nuclei of meaning which gave rise to this category were based in the accounts which emphasized themes relating to the search for growth and learning and for supporting the work group. The challenge of being a leader is understood as a growth opportunity; however, one can perceive the ambiguity experienced in the management position, as, at the same time as it creates fear, this is a condition which drives the search for new knowledge and 'enriches' the subject in the position: It's a really rich opportunity, but sometimes people are scared of facing this challenge (N27).

Fear of change leads to stagnation and reaffirms the status quo, being an obstacle to individual and collective growth; however, the versatility of the hospital environment challenges the leaders so that they encourage their peers such that they become involved in the new realities ${ }^{(9)}$. In spite of this, the desire to change and cause changes is positioned on a fairly tenuous line between fear and pleasure and, according to this logic, the challenge of solving problems in the daily work encourages the overcoming of problems and opens up new possibilities, as follows: What encouraged me to take on a management position was the challenge, overcoming issues at a personal and professional level. [...] the responsibilities and the problems fascinate me in a certain way (N31). For me, it was a great challenge, to stir things up which were stagnating (N29).

Another aspect verbalized as important by the nurses is grounded in the fact that the people felt supported by the members of the group with whom they worked, strengthening them for managing the activities: If you don't have the workers' support, you can't manage well (N2). It was because of encouragement from the workers themselves that I interviewed for the management position, and, also, my colleagues encouraged me to stay in that position. For me, the main thing is this: it was the strength on the part of the personnel who I was going to be dealing with [...] (N8).

The construction of relationships of trust and respect between members of the nursing team can help in the valorization of the organizations' social capital and in the strengthening of the cooperative, supportive networks 
and with shared values. This condition helps the groups to face situations which change constantly, assisting in the recognition of those in whom one can trust and on whom one can rely in order to overcome difficulties ${ }^{(10-11)}$. However, for the nurse in a management position to be able to rely on the support of her group it is important for her to promote a dynamic which is not restricted to simply engaging with it, creating good channels of communication and relating adequately to all with the aim of having them as allies. In a genuine participative process, it is necessary to have characteristics which, fundamentally, prioritize ethics and the collective construction of the subjects. It is supposed that, in this way, people feel involved and motivated to achieve objectives and goals, achieving the best results.

\section{The view of the nursing middle management on the exercising of leadership}

The themes detailed by the interviewees as important requirements for occupying a leadership position, and which configure the nuclei of meaning for this category, were: pleasure and identification with the practice of management and leadership, the desire to contribute to the organization based on solid professional experience, as well as the competency to lead a work group, besides decision-making ability, commitment and responsibility.

In addition, the establishment of a close relationship between the functions of middle management, management and leadership was shown by various nurses: Leadership is a thing I like too, decision-making, all that side of management (N4). I like carrying out matters related to consensus, strategies, and planning (N24). I try to be clear as to my role in leadership, or in management (N12).

In spite of the interwoven relationship between concepts, the leader is understood by the nursing professionals as somebody who helps, who listens, who collaborates in the daily routine of the work, who commands well - and the boss is understood as somebody who simply gives orders, who makes people follow the rules, who threatens, who is decisive and

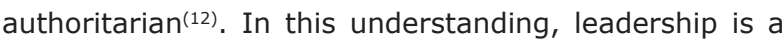
more affective and comprehensive role, while the boss is limited to commanding and controlling.

It is stressed that management and leadership, in nursing, are commonly used as similar terms, leadership being a support for the practice of nurses in management roles or with administrative responsibilities ${ }^{(13)}$. It should also, however, be emphasized that the leadership process does not take place only in formal and hierarchical situations defined by job titles or positions. The need to develop competences, skills and attitudes which qualify the leadership process in the groups, as with the management processes, was equally recognized by the nurses: Making each one take on responsibilities. [...] It's not me [head of the center] who has to go there and detect that the member of staff from that group is late. You also are important, you too have to participate in this process (N12). I think it's a big responsibility to have an administrative activity, it requires humanity, to lead a work group (N3).

The nurse occupies a space in the health systems' structure which provides her with the opportunity to be in a leadership position in the nursing team, as well as in other health teams, in the organizational processes. Recognizing and appropriating this place, as well as using it for optimizing the leaderships within the work teams, is a sensible choice which can represent a big advance for the profession and qualification of the health actions. In encouraging shared leadership practices in the teams, one can promote the development of more cooperative and integrated ways of working.

Professional experience and the desire to contribute, anchored in knowledge acquired over years of experience in the institution, were stressed as fundamental aspects for the nurses to perceive themselves as ready to face challenges and become leaders in strategic organizational positions, as found in the following accounts: I sincerely consider myself to have the conditions, I wouldn't say completely, totally, but with a very good background, rich in knowledge, with lots of experience (N12). I felt I was able to take on the center, because I've been working for years and I have a lot of experience. I felt that my time had come (N8).

It was extracted from the accounts that the day-today of the work of the center's head is complex and full of situations which require her common sense, skill in getting on with others, managing conflicts, planning and achieving results, among other issues, a dynamic which can be improved in acting with knowledge and knowing with action.

\section{The emblematic aspect of working with people}

In the accounts, the nurses in the position of head of unit emphasized the dynamic of working with people, having reported to the groups and to the individuals as subjects articulated in complex relationships, converging on this category's nuclei of meaning. The verbalizations on this issue denote contradictions, as, at the same time that interpersonal relationships are mentioned as stimulating and motivating, due to the diversity, they 
cause apprehension and a certain desire for uniformity: The main difficulty in being the head is knowing how to manage to work with the diversity. You have to know how to deal with each person in a different way (N10). Principally in the interpersonal relationship, which is a really difficult thing, but when we manage to get the group to pull in the same direction, that makes you very satisfied (N13). For me, it's pleasant, this work is exciting, it's about relating to people, building, having an idea for resolving a problem, creating, bringing together (N9).

The emphasis on the challenge of working with people, that is, the organizations' human capital, has been indicated in various studies ${ }^{(11,14)}$. It is added that investing in the individual and collective potential in the work groups can help in the construction of more creative and innovative management models, able to respond to the constant transformations of settings in the health systems.

In the XXI century, transformational leadership has been shown to be a strategy capable of promoting changes in healthcare systems, through the optimization of the intra- and inter-team communication processes, creativity, innovation and autonomy in decisionmaking(14). The nurses who noticed and developed such skills, in the groups, will be able to contribute to the construction of relationships of trust, respect, recognition and collaboration, in a transformational model - but, above all, in a model which prioritizes participative actions of leadership.

It is advantageous to highlight that the establishment of shared partnerships, efforts, information and power can increase the professionals' satisfaction and result in benefits for the work environment and for the patients ${ }^{(15)}$.

These considerations reflect the complexity of the processes of leadership in nursing, in which the work results, fundamentally, from interactions between people, both in the multi-disciplinary and the interdisciplinary perspectives, with the aim of producing care actions for individuals, who are also complex beings, articulated with other social groups.

\section{Leadership in nursing - mediatory and conciliatory}

The work of the nurse as an articulator in the midst of situations of tension between individual, group and organizational interests was an issue emphasized in the accounts in which conflict and power are highlighted, delineating this category's nuclei of meaning.

Since the pioneering work of Max Weber in the conception of authoritarian, democratic and liberal styles of leadership, contemporary society has followed the evolution of these concepts applied to organizations, and today there are various classification systems for dimensioning the exercising of leadership ${ }^{(12)}$.

In the interviews, emphasis was placed on characteristics of conciliation and mediation in the leader's attitude and behavior, as head of a group: Conciliating the interests of your work group, [...] with what has been determined by the middle management, you have to be very flexible for this (N3). The biggest difficulty is making the interface between what the Institution demands, calls for, and what is really possible to operationalize (N19). I am the intermediate, I have to be this link between the employee to provide the care and, at the same time, the institution, so that it may achieve its objectives, the goals within the planning, within a strategic map (N12).

The information which gives importance to this category reflects very incisive issues of leadership, such as power and conflict. The way of dealing with the conflict is related to the manners of using power which are adopted by the managers, and may be manifested in the hindering, negociatory, accomodatory or collaborative styles, which may be determinant in the conduction of conflict situations. Added to this consideration is that it is relevant to adopt a pluralist perspective for dealing with the conflicts, accepting the diversity, in that different people may have different ideas, values and beliefs which reflect peculiar ways of seeing life ${ }^{(12)}$. The following accounts denote this concern: As a manager, I can have more access to review the process and have greater power to change some lines of work (N33). Power to participate more actively in the decisions referent to the unit. We start to deal more with the staff, to know the managers of the other areas, of the stores, of engineering, we begin to be able to give opinions more on the issues which will happen or be changed (N27).

The leadership, therefore, is understood as a group phenomenon, taking into account that how the leader behaves and articulates her actions is reflected in the team's work process. Emphasis is placed on selfknowledge as a condition sine qua non for the exercising of leadership, as it makes it possible to recognize one's own skills and those of others, improving them, as well as identifying weak points and seeking to overcome them. In addition to this, based on dialog, exchange and cooperation from the group itself, it is possible to break, from the top down, with old concepts and structures which are based in bossy practices, creating a healthier, more dialogic and liberating organizational climate(16).

The hospital institutions have adhered to a new, more flexible, organizational culture, based in negotiation and in the professional growth of its members. The nurse leader must be ready to effect changes not only in the 
more general ambit of the organization, but also in what is happening in the group relations, in relation to aspects such as motivation and satisfaction ${ }^{(16)}$. Thus, conciliatory and mediatory attitudes are essential for maintaining a healthy and productive workplace environment.

\section{Time: a dilemma between managing and caring}

In this category, the nuclei of meaning, in their centrality, express accounts related to the heads' experiences in the double requirement to manage and care - and how they organize their actions in consonance with the institutional mission.

In addition to lack of time for the nurse in the management position to meet both managerial and assistential needs, emphasis was placed on establishing priorities in the work, based on thorough planning, so as to undertake the truly essential activities and, with this, make better use of the time. In the interviews, it was indicated that the nurse in charge of the unit should be dedicated to that job alone, and not accumulate management and care functions, as had been happening: I think that if the head of the unit only did management tasks, it would be better (N2). Because I think that the person has to be exclusively in this position, when they take on a management role (N13). What I lack is time for planning, to see what needs improving (N12).

In other hospital contexts there is a differentiation in the exercising of these functions, there being nurse managers and nurses who provide care. Such a configuration was described in a study ${ }^{(17)}$ undertaken in a public hospital, where nurses who took on exclusively management positions experienced a polarization between care provision and management, that is, a dilemma between being a nurse providing care or being a manager, even when both roles are not mutually exclusive. It was considered, further, that the nurse who takes on purely the condition of being a head needs "to understand that the contact with the front line is no longer made by him, but through the people he manages, being co-responsible for the whole sector"(17). In contradiction to this, also in the field of the present study, one may find accounts which argued in defense of maintaining the link with assistential activities, as this experience provides support for strengthening their functioning in the sectors' managing: I think it's incredibly important that you don't stop being involved in care provision, so we don't lose this knowledge, so that we can experience and relate. Even, so that we can assert our rights, so as to win, negotiate. But I would need more time (N12)
Mastery of care has been recognized as essential for management, although not sufficiently for this practice to be successful. Excellence in clinical practice is considered to be a fundamental factor for the nurse to be accepted for leadership of the team and for the development of potential leaders. A nurse with mastery of assistential knowledge to has the opportunity be closer to the team's needs, and to be a source of motivation for the same ${ }^{(6,13)}$

In the accounts, emphasis was placed on the administrative actions undertaken by the center's middle management, such as archiving documentation, preparing reports and controlling the attendance of the nursing personnel - which, in the hospital where the study took place, is presented and managed via a system termed Ronda: We are always running, in a certain way, after the machine, because of the reports, from that Ronda (N6). You have to forward the holiday plans, do the off-duty, 'balancing up' the Ronda (N2). My role goes far beyond balancing the Ronda at the end of the month and I don't have enough time to do everything how I would like (N12).

The emphasis placed on these items reflects the idea that the functioning of the center's managers is restricted to meeting strictly bureaucratic demands; however, it is important to bear in mind that the functioning of the leader involves developing an action plan in conjunction with the work team, guiding, motivating, and proposing improvements which may lead to more favorable results. The actions exemplified by the interviewees, although conceived of merely as tasks, are part of the planning and support the sector's assistential activities.

Considering the direction given by the nurse managers, it is considered whether the lack of time has to do with an overburdening with activities, difficulty in time management, or, further, whether it is related to the daily facing of the job of being the manager of the unit. In addition to this, the challenges intrinsic to the position begin with adequately organizing the time itself, between what is prescribed and known, in dealing with activities relevant to the position, and what emerges in the routine and is, therefore, unknown and unpredictable.

\section{Final Considerations}

In finalizing this article, it is stressed that the position of management reflects the challenge of being a leader, understood as a growth opportunity; however the ambiguity experienced in such a strategic position is 
emphasized. At the same time that it creates fear, it is thought that this is a condition which drives the search for new knowledge, making possible the progressive qualification of the subject for the position.

In relation to the motivation to take on the management position, the same is permeated by contradictions, drawing one's attention to the emblematic aspect of working with people and developing the skills for managing conflicts resulting from these complex relationships, in a constantlychanging environment. It emerged from the study that, although the interpersonal relationships are stimulating and motivating, due to their diversity, they cause apprehension and a certain desire for uniformity - a becoming accustomed to, and satisfied with, the status quo. It was also seen that administration of the time tests the ability of nurses in management positions to deal with multiple demands, establish priorities, innovate in solutions to old problems, define goals, and flexibilize and (re-) direct their own work.

By way of final considerations, it is pointed out that conciliatory and mediatory attitudes are fundamental for a healthy and productive organizational climate. In addition to this, it is thought that reflecting on the competences of the nurse in strategic positions of management is fundamental for the profession to advance, considering the emphasis on collective work in the health services. This is an especially important condition in the ambit of the university hospitals, taking into account that, besides care provision and research, these hospitals have an inalienable commitment to training human resources.

\section{References}

1. Decreto n. 7.082 de 27 de janeiro de 2010 (BR). Institui o Programa Nacional de Reestruturação dos Hospitais Universitários Federais - REHUF. 2010. [acesso 9 out 2012]; Diário Oficial da União. [Internet]. Disponível em: http://www.planalto.gov.br/ccivil_03/_ Ato2007-2010/2010/Decreto/D7082.htm

2. Machado SP, Kuchenbecker R. Desafios e perspectivas futuras dos hospitais universitários no Brasil. Ciênc Saúde Coletiva. 2007;12(4):871-7.

3. Abrahão, AL. Colegiado gestor: uma análise das possibilidades de autogestão em um hospital público. Ciênc Saúde Coletiva. 2008;13(1):95-102.

4. Spagnol CA, L'Abbate S. Conflito organizacional: considerações teóricas para subsidiar o gerenciamento em enfermagem. Cienc Cuid Saúde. 2010; 9(4):822-7
5. Lanzoni GMM, Meirelles BHS. Leadership of the nurse: an integrative literature review. Rev. Latino-Am. Enfermagem. 2011; 19(3):651-8.

6. Moura GMSS, Magalhães AMM, Dall'agnol CM, Juchem BC, Marona DS. Leadership in Nursing: Analysis of the Process of Choosing The Heads. Rev. Latino-Am. Enfermagem. 2010; 18(6):1099-1106.

7. Minayo MCS. O desafio do conhecimento: pesquisa qualitativa em saúde. 12. ed. São Paulo (SP): Hucitec; 2010. 407 p.

8. Resolução n. 196 de 10 de outubro de 1996 (BR). Dispões sobre as diretrizes e normas regulamentadoras de pesquisa envolvendo seres humanos. 1996. [acesso 09 out 2012]. Diário Oficial da União. [Internet]. Disponível em: http://conselho.saude.gov.br/resolucoes/reso_96. htm

9. Furtado LCR, Batista MGC, Silva FJF. Leadership and job satisfaction among Azorean hospital nurses: an application of the situational leadership. J Nurs Manag. 2011; 19:1047-57.

10. Dols J, Landrum P, Wieck KL. Leading and managing an intergenerational workforce. Creat Nurs. 2010; 16(2):68-74.

11. Moura GMSS, Inchauspe JAF, Dall'Agnol CM, Magalhães AMM, Hoffmeister LV. Expectativas da equipe de enfermagem em relação à liderança. Acta Paul Enferm. 2013; 26(2):198-204.

12. Stanley D. Congruent leadership: values in action. J Nurs Manag. 2008; 16(5):519-24.

13. Nienaber $\mathrm{H}$. Conceptualisation of management and leadership. Manag Decision. 2010; 48(5):661-75.

14. Sorensen EE, Delmar C, Pedersen BD. Leading nurses in dire straits: hear nurses' navigation between nursing and leadership roles. J Nurs Manag. 2011; 19:421-30.

15. Vendemiatti $M$, Siqueiro $E S$, Filardi $F$, Binotto $E$, Simioni FJ. Conflito na gestão hospitalar: o papel da liderança. Ciênc Saúde Coletiva. 2010; 15(Supl. 1):1301-14

16. Amestoy SC, Cestari ME, Thofehrn MB, Milbrath VM. Características que interferem na construção do enfermeiro-líder. Acta Paul Enferm. 2009; 22(5): 673-8. 17. Motta KAMB, Munari DB, Costa FN. Os pontos críticos das atividades do enfermeiro gestor no hospital público. REPSIPP. 2009; 1(1):73-99.

Received: Dec. $5^{\text {th }} 2012$ Accepted: July $15^{\text {th }} 2013$ 